\title{
A FALTA DE HOMENS DE LETRAS: A EDUCAÇÃO NO CONTINENTE DE SÃO PEDRO DO RIO GRANDE DO SUL (1770-1834)
}

\author{
Eduardo Arriada ${ }^{1}$ \\ Universidade Federal de Pelotas-UFPEL \\ Hardalla Santos do Valle ${ }^{2}$ \\ Universidade Federal de Pelotas-UFPEL
}

\section{RESUMO}

O presente estudo tem como objetivo abordar como ocorreu o processo das aulas régias no Continente de São Pedro, enfatizando qual o perfil dos educadores presentes nesse contexto. Assim sendo, as questões que nortearão esse estudo, serão: Como se deu a formação intelectual nesse território durante o período colonial? Quais sujeitos históricos atuavam nesse processo educacional? Quais elementos delineavam a identidade desses educadores? Que saberes escolares eram ministrados? É importante mencionar que enquanto obrigação do estado, a instrução pública rio-grandense foi tardiamente implantada. Tal fato delineia um contexto díspar que merece ser estudado. Na busca por possíveis respostas, estaremos pautados na metodologia da pesquisa histórica documental.

Palavras-chave: Continente de São Pedro, aulas régias, mestres-escolas, educação colonial.

\section{LACK OF MEN OF LETTERS: EDUCATION IN THE CONTINENT OF PETER THE RIO GRANDE DO SUL (1770-1834)}

\section{ABSTRACT:}

This study aims to address how the process occurred in the mainland of the royal schools of St. Peter, emphasizing what the profile of teachers in this present context. Thus, the questions that will guide this study are: How did the intellectual training that territory during the colonial period? What historical subjects worked in the educational process? What elements outlining the identity of these educators? What school knowledge were taught? It is important to mention that as an obligation of the state, public education Rio Grande was later deployed. This fact outlines a framework disparate worth studying. In the search for possible answers, we will be guided by the methodology of historical research documents.

Keywords: Continent of St. Peter, royal schools, schoolteachers, colonial education

\section{Introdução}

O Continente de São Pedro é fruto de uma forte política expansionista do Império Luso. Sua primeira expressão foi o paulatino processo de ocupação de terras, em decorrência de invasões marcadas pela violência e doações das sesmarias, o qual definiu a presença portuguesa no território. Essa ocupação se deu num espaço rural com a forte presença das estâncias. Com isso o ambiente caracterizado pela vasta extensão de latifúndios, estava afastado dos núcleos urbanos. Paralelamente, a elite latifundiária pretendendo estender a manutenção de seu poder - não era desejosa de instigar uma educação letrada para o povo. Com efeito, a oferta de pessoas habilitadas para o exercício do letramento era escassa, dificultando as relações de ensino intelectual. 
A partir disso, o presente artigo almeja discorrer acerca do processo de desenvolvimento das aulas régias no Continente de São Pedro, enfatizando qual o perfil dos educadores presentes nesse contexto.

Nessa perspectiva, apresentamos as seguintes inquietudes como norteadoras desse trabalho: Como se deu a formação intelectual nesse território durante o período colonial? Quais sujeitos históricos atuavam nesse processo educacional? Quais elementos delineavam a identidade desses educadores? Que saberes escolares eram ministrados?

O meio escolhido de nos aproximarmos dessas respostas foi, primeiramente, a pesquisa bibliográfica, a qual possibilita ao pesquisador entrar em contato direto com tudo que foi escrito acerca da temática almejada. Bem como, pesquisa histórica documental, que proporciona o trabalho com materiais textuais escritos.

Paralelamente, é importante lembrar que o objetivo dessa construção, além de investigar a história da educação do período colonial, é enfatizar a atuação dos "mestresescolas". Assim sendo, a periodização estabelecida tem como pressuposto as primeiras escolas mantidas pelo poder público, ou seja, a Escola de Meninos e o Recolhimento de Meninas, criados na Aldeia de Nossa Senhora dos Anjos; e o Ato Adicional de 18, que definitivamente elimina o modelo de Aulas Régias. Fatos que serão expostos do decorrer desse trabalho.

\section{O Continente de São Pedro do Rio Grande do Sul}

O processo de ocupação e povoamento do extremo sul do Brasil foi decorrência de uma política expansionista do império luso. Em seu início foi lento, somente com a fundação de Rio Grande, em 1737, começa uma efetiva posse do território, essa ocorrerá pela doação de imensos latifúndios - as sesmarias -, ou simplesmente pela apropriação violenta e predatória. Pouco a pouco temos a penetração do elemento português nessa vastidão de planície entrecortada de arroios, riachos, sangradouros, lagoas e rios.

Os primeiros núcleos que marcam a presença dos lusos em território sulino vão surgindo. A pequena povoação do Rio Grande é elevada a vila em 1747, em 1741, temos a criação da capela de Viamão e surge o Porto dos Casais no ano seguinte. Os açorianos espalham-se pelo Rio Grande e breve estarão recebendo lotes de terras ao longo do vale do Jacuí e nas zonas litorâneas.

Vários autores na época condenavam a prática de distribuição de terras, em fins do século XVIII, Magalhães (1940, p.57) frisava: “[...] o abuso que há nesta Capitania de terem alguns moradores tomado três, quatro sesmarias com dez, doze e mais léguas de terras é prejudicialíssimo não só a S.A.R., mas aos povos em geral; ao mesmo tempo que há famílias que não possuem um palmo".

Nesse mundo rural, a estância, além de ser sede de imensos latifúndios estava longe dos núcleos urbanos, portanto devia ser auto-suficiente. Isso propiciou uma situação peculiar, pois era composta por uma multiplicidade de espaços, decorrentes das funções que abrigava. Nas estâncias havia uma estrutura econômico-social de trabalho. Além do estancieiro, do capataz e dos peões, havia uma ação complementar, a dos posteiros, a dos negros escravos, estes geralmente ligados à lavoura de subsistência e/ou a pequenos trabalhos domésticos.

$\mathrm{Na}$ viagem empreendida em 1820, ao Rio Grande do Sul, Saint-Hilaire deixou registrado a impressão causada por essas estâncias:

Nesta região, a pecuária quase não exige cuidado; deixam os animais vaguear pelos campos e não há necessidade, como acontece em Minas, de dar-lhes sal. A única preocupação que 
julgam necessária consiste em acostumá-los a ver gente e a entender-lhes os gritos, para que não fiquem completamente selvagens, se deixem marcar, quando necessário, e possam apanhar os que se destinarem ao corte e à castração.(SAINT-HILAIRE, 1987, p.26).

Região constantemente envolvida em guerras, as lutas fronteiriças com a Espanha, marcaram de forma contundente essa realidade. Mesmo com a iniciativa da colonização açoriana no século XVIII, onde os portugueses tentam introduzir a pequena propriedade, foi a grande propriedade rural e a criação de imensos rebanhos que acabou prevalecendo.

Não existia interesse dessa elite latifundiária de propiciar uma educação letrada para seus subordinados. Sabendo pastoriar, laçar, domar e outras atividades campeiras, já era o suficiente. $O$ que acabava produzindo um discurso da não necessidade de uma instrução escolar.

Os relatos de diversos viajantes que percorreram a Província no século XVIII e XIX observaram esse fato. O português Ferreira de Souza (1979; p.242) registra em 1777: "[...] laçar, andar a cavalo, correr, fazer parelhas, e arreiar é o destino em que se empregam [...] brutalmente passam, brutalmente vivem, e brutalmente morrem."

Dentro do contexto brasileiro, o Rio Grande do Sul estruturou-se como uma economia agropastoril, subsidiária da economia agroexportadora, voltada para o mercado interno.

Esse tipo de estrutura produtiva dificultava sobremaneira a implantação de um sistema educacional. "Durante quase um século, que mediou entre a fase inicial do povoamento e o estabelecimento das primeiras aulas de ler e escrever o Rio Grande viveu em absoluta ignorância, por falta de meios rudimentares de instrução" (PORTO, 1935, p.237).

\section{O período das Aulas Régias}

Durante muito tempo o Continente de São Pedro esteve excluído do subsídio literário. Sua aplicação no Brasil decorre da lei de 1772, contudo o relatório do Vice-Rei Marquês de Lavradio de 1773 estabelecia que essa legislação não fosse aplicada no Continente.

Por sua vez, o Relatório apresentado ao Governo de Lisboa pelo Vice-Rei Luiz de Vasconcellos, de outubro de 1784, sobre o Rio Grande, demonstrava algumas preocupações relativamente à educação. Embora a política de Portugal estivesse voltada para a defesa e desenvolvimento da economia, não deixavam de demonstrar um interesse pelo ensino. De acordo com o relatório, existiam "naquele Continente duas Aldeias". A primeira era a de Nossa Senhora dos Anjos, e a segunda de São Nicolau, nelas estavam estabelecidos diversos índios, devendo o administrador acolher "Mestres de Escola, Gramática e Solfa." (VASCONCELLOS, 1929, p.33).

Deste modo, além de estar numa situação periférica em relação ao centro do império colonial português, a política de subsidiar a educação não incluía o Rio Grande, ficando sem os recursos financeiros do erário público. As primeiras iniciativas públicas foram a Escola de meninos e o Recolhimento de meninas, ambos criados na Aldeia dos índios guaranis de Nossa Senhora dos Anjos em 1770. Embora possamos louvar essa iniciativa por parte do Governador José Marcelino de Figueiredo, o resto da população não recebia qualquer ajuda, o que levou o Vice-Rei do Brasil a declarar: 
Quanto as Escolas de ler, Gramática, e Solfa, sendo um estabelecimento, que a primeira vista parece proveitoso não é ali o mais próprio para serem as utilidades correspondentes as despesas e ao trabalho. [...] Que bem empregado seria todo o cuidado que pôs aquele Governador na educação dos índios, se o voltasse para qualquer das outras povoações do Continente, que se acham sem mestres para a educação da mocidade, e nela fizesse também instruir os índios, que mostrassem inclinação nos estudos. [...] Esta providência, que abrangia a muitos filhos do Continente, não podia deixar de produzir um conhecido adiantamento; e eu a teria procurado por em execução, se para se estabelecerem escolas públicas, com ordenados e mestres, não se fizesse necessária toda a resolução de $\mathrm{S}$. Mag. a este respeito, da qual achou aquele Governador não depender, para tomar despoticamente o arbítrio de erigir na referida Aldeia as sobreditas escolas, de que ele mesmo não podia deixar de conhecer o pouco, ou nenhum progresso. (VASCONCELLOS, 1929, p.34-35).

O Continente de São Pedro do Rio Grande do Sul, mais tarde Província do Rio Grande do Sul, teve durante muito tempo uma precária formação intelectual, sendo tardia a implantação de um sistema público de educação, em relação ao resto do país. Zona fronteiriça, durante a maior parte de sua história, esteve envolvida em disputas territoriais com espanhóis e, posteriormente, seus descendentes. Para agravar mais essa situação a aprovação da lei que estabelecia o subsídio literário de 10 de novembro de 1772, por determinação do Marquês do Lavradio excluía o Continente de São Pedro. Essa restrição só vai cessar com o Decreto de 24 de novembro de 1813, que mandou aplicar ao Continente a lei de 1772, cobrando-se o subsídio "à razão de 320 réis por cada rês que se matarem para vender tenham ou não 10 arrobas cada uma e 10 réis por cada medida de aguardente, regulando-se isto pela canada de Lisboa" (ROSA, 1948, p. 175).

Apesar desse contexto desfavorável, há registros da atuação de diversos mestres nas Vilas, ministrando aulas de "primeiras letras" e de "gramática latina", após a autorização da respectiva Câmara. Temos referência, por exemplo, de Vitorino Pereira Coelho, nomeado a 19 de junho de 1790 para a cadeira de latim, com o ordenado anual de 240\$000 (ABREU E SILVA, 1922, p. 31).

Somente com essa Reforma de 1772, será instituído um sistema de ensino verdadeiramente estatal. Com a criação do subsídio literário, tributo exclusivamente voltado para a subvenção da rede de escolas então estabelecidas pelo Estado. Deste modo, os professores passam a ser funcionários públicos.

As reformas pombalinas em maior ou menor grau acabaram sendo influenciadas pelos "estrangeirados", isto é, portugueses que por diversas razões tiveram que viver fora de Portugal, absorvendo em graus variados as influências do pensamento iluminista. Para Boto (2004, p.172): “[...] o pombalismo português e seu declarado intento de secularização do ensino constituíram inegavelmente um debate de vanguarda no que diz respeito a políticas públicas de escolarização".

Entre as várias reformas estabelecidas por Pombal, a Reforma da Universidade de Coimbra em 1772 foi fundamental. Visava entre outros aspectos, promover aquilo que na época permeava os debates políticos, isto é, possibilitar o progresso do Estado. 
Um dado apontado por Carvalho (1996, p.62), é relevante para a realidade da Província de São Pedro, isso se refere ao baixo número de sul-rio-grandenses em Coimbra, isso para o autor revela o isolamento da Província e seu problemático relacionamento com o governo central.

A expressão aulas régias, que em princípio durou de 1759 até 1822, quando passam a serem denominadas aulas públicas, permaneceu mesmo assim durante muito tempo na história da educação com o primitivo nome.

Pela Reforma de 1759, a designação de Estudos Menores, como aparece nos documentos oficiais deste período, do mesmo modo que a de Escolas Menores, e de Primeiros Estudos, correspondia ao ensino primário e ao ensino secundário, sem distinção.

O sistema de ensino implantado com a Reforma dos Estudos Menores de 1759 baseava-se, portanto, nas Aulas de primeiras letras e nas Aulas de humanidades, que eram denominadas de maneira geral de Aulas Régias. [...] As Aulas Régias significavam as Aulas que pertenciam ao Estado e que não pertenciam à Igreja. (CARDOSO, 2004, p. 182).

Dentro do espírito da época, essa educação não era de caráter obrigatório, sabendo diante-mão o próprio governo que era impossível montar uma rede escolar nas colônias, seguia na prática, o discurso elaborado pelos iluministas, para a maior parte da população bastaria "ler, escrever e contar"; para a elite ilustrada, ai sim, uma educação secundária, visando, posteriormente, cursar o ensino superior no Reino.

Tentando superar, ou quem sabe, ao menos minorar a precariedade da instrução pública, Paulo José da Silva Gama, ao assumir o governo no ano de 1803, toma algumas medidas. Em sua opinião "[...] só esta capitania, com vergonha e dano incalculável de seus habitantes, jaz como em letargo, ignorado talvez até a necessidade que tem de instruir seus filhos" (GAMA, 2008, p.54). Reorganiza as diversas instâncias do poder, no intuito de criar a infra-estrutura mínima à administração pública no Continente. Ao final de seu primeiro ano, estabelecia um plano para o ensino público.

Inicialmente, caracterizava o seu entendimento sobre a educação: “[...] que a educação da mocidade seja a base mais sólida dos impérios e a fonte inexaurível da felicidade pública, não é um problema, é antes uma verdade". Assim como, na sua percepção: "[...] da atenção ou negligencia deste importantíssimo objeto, é que derivam as virtudes e os vícios, os bens e os males, que ora elevam ora abatem as nações". Para ele, a falta de uma boa educação, não haveria bons costumes, e desse modo, "[...] ninguém saberia ser nem bom cidadão, nem bom vassalo". A educação é, pois essencial à constituição e segurança dos estados, "[...] nada mais digno da vigilância e desvelos dos que governam”. (GAMA, 2008, p.54).

Após detalhar em minúcias o papel relevante de cada disciplina, apresentava indicações onde deveriam ser estabelecidas as escolas, no caso: Porto Alegre, Rio Grande e Rio Pardo. Igualmente, valorizava sobremaneira o ensino da língua materna, sem, contudo descurar o ensino do francês, do latim e das matemáticas. Muitas das medidas administrativas de seu governo, mais tarde seriam efetivamente implantadas, mesmo assim, sua administração balizou os futuros governantes do Continente, mormente após a vinda da Família Real. 
[...] A mocidade deveria passar primeiramente a instruir-se na sua língua materna, para evitar o opróbrio de falar corruptamente a sua própria linguagem, como pela maior parte infelizmente acontece no Brasil. Seguir-se-ia imediatamente o estudo da língua francesa, [...] esta cadeira de Gramática Portuguesa e Francesa existiria na Vila Capital de Porto Alegre e o seu professor venceria de ordenado anual $300 \$ 000$ réis. (GAMA, 2008, p.55).

Por fim, tendo esse domínio da língua portuguesa e francesa, o aluno passaria ao estudo da gramática latina, "que nos abre a porta para estudarmos os sublimes modelos da antiguidade". Paralelo estaria o ensino da filosofia racional e moral, visando "desenvolver as idéias e criar o entendimento e o espírito". Como coroamentos dessa formação estudariam aritmética, primeiros elementos de geometria e trigonometria, "[...] que acostumando o espírito a demonstração e a discorrer sucessivamente e com ordem por meio de combinações [...] disporia tão vantajosamente a mocidade para qualquer profissão". (GAMA, 2008, p.55).

A postura adotada por Paulo Gama estava de acordo com o ideário iluminista, fruto do reflexo das reformas pombalinas no Brasil. Na obra o "Verdadeiro método de estudar" de Luís António Verney, explícito está à valorização da língua nacional em detrimento do latim. "O primeiro princípio de todos os estudos deve ser a gramática da própria língua. [...] Julgo que este deve ser o primeiro estudo da mocidade, e que a primeira coisa que se lhe deve apresentar é uma gramática da sua língua, curta e clara. (VERNEY, s/d, p.68-69).

Em sua proposta, Paulo Gama esclarecia de onde proveriam os fundos que subsidiariam a instrução pública: "imposição de um real em cada libra de carne vendida nos açougues." (GAMA, 2008, p.56).

Em 1808, Manoel Antônio de Magalhães escreve um relato sobre a Vila de Porto Alegre, com reflexões sobre o estado da Capitania do Rio Grande do Sul. Entre as diversas observações feitas, numa delas comenta a atuação do Governador (no caso Paulo Gama): "[...] o presente governador é um homem muito hábil e criador, amigo dos interesses de seu príncipe e dos povos; ele tem trabalhado quanto lhe é possível pelo adiantamento da Capitania, ao ponto de tirá-la do letargo em que jazia [...]". (MAGALHAES, 1940, p.61).

Deixou ainda outra observação rara e pertinaz sobre a educação da época: "Há uma aula publica de gramática, e duas escolas de ler e escrever, em uma d'elas contei eu sessenta e três meninos de sete e doze anos". (MAGALHÃES, 1940, p.71).

Essa inoperância do poder público foi vigorosamente criticada pelo Governador José Feliciano Fernandes Pinheiro:

Até ha pouco se contava apenas um professor de gramática latina, instituído pelo Estado, na capital de Porto Alegre, e por uma contradição incompreensível a mocidade, esperanças da Nação, parecia abandona à mais crassa ignorância, e barbaria; só no ano de 1820 é que foram outorgadas e providas algumas das cadeiras. $\mathrm{O}$ interesse bem entendido da civilização insta, que se difundam e multipliquem Escolas menores de ler, escrever e contar, debaixo de bons métodos, por todas as Freguesias da Província. (PINHEIRO, 1822, p.108). 
Embora suas preocupações estivessem mais comprometidas com a difusão das "escolas menores", enquanto homem público e administrador da Capitania ${ }^{3}$ não deixava de aventar a possibilidade de implantação das "escolas maiores":

Quanto ao estabelecimento de Escolas maiores, nas quais se propague a instrução, já do que tende a ornar o espírito, e formar o gosto, já daquelas noções e princípios, que mais direta e vivamente influem sobre a prosperidade nacional, é excelente o projeto de um Ginásio ou Colégio em cada Província; nada mais digno dos desvelos dos que governam. (PINHEIRO, 1822, p.109)

No seu entender, a razão da Província não ter sido contemplada com o subsídio literário devesse:

A conjuntura crítica da guerra e desolação, em que se achava está Província, quando se promulgou a Lei de novembro de 1772, foi o motivo de ser interinamente excetuada do Imposto e Coleta aplicada para manutenção dos professores das escolas menores; por fim em março de 1814 foi aqui estabelecido o Subsídio Literário [...]. Está calculado, que as somas, a que anualmente monta a coleta, são suficientes para sustentar o ensino elementar nesta Capitania. (PINHEIRO, 1822, p.109).

Durante a sua administração, por fim, sai à nomeação para a criação de diversas cadeiras, conforme resolução de 07.02.1820. "Hei por bem criar as Cadeiras, que constam do vosso plano, com os ordenados nele indicados, as quais serão providas por concurso feito perante vós $[\ldots] "$ ".

Relação das Cadeiras mencionadas no plano:

Aulas de Primeiras Letras

\begin{tabular}{|c|c|}
\hline Capital de Porto Alegre & Honorário de $\mathrm{R} \$ 250 \$ 000$ \\
\hline Vila do Rio Grande & Honorário de $\mathrm{R} \$ 200 \$ 000$ \\
\hline Vila do Rio Pardo & Honorário de $\mathrm{R} \$ 200 \$ 000$ \\
\hline Vila de Santo Antônio & Honorário de $\mathrm{R} \$ 150 \$ 000$ \\
\hline Freguesia de S. Francisco de Paula & Honorário de $\mathrm{R} \$ 100 \$ 000$ \\
\hline Vila da Cachoeira & Honorário de $\mathrm{R} \$ 100 \$ 000$ \\
\hline Freguesia do Triunfo & Honorário de $\mathrm{R} \$ 100 \$ 000$ \\
\hline
\end{tabular}


Província de Missões

Honorário de R \$100\$000

Aulas Maiores

\begin{tabular}{|l|l|l|}
\hline Capital de Porto Alegre & Gramática Latina & Honorário de R\$300\$000 \\
\hline Capital de Porto Alegre & Filosofia Racional e Moral & Honorário de R\$300\$000 \\
\hline Capital de Porto Alegre & Retórica & Honorário de R\$300\$000 \\
\hline Capital de Porto Alegre & $\begin{array}{l}\text { Aritmética, álgebra, } \\
\text { geometria, e trigonometria }\end{array}$ & Honorário de R\$400\$000 \\
\hline Rio Grande & Gramática Latina & Honorário de R $\$ 250 \$ 000$ \\
\hline Rio Pardo & Gramática Latina & Honorário de R $\$ 250 \$ 000$ \\
\hline
\end{tabular}

Fonte: PINHEIRO, 1822: anexo F.

Durante muito tempo, a formação intelectual no sul do Brasil foi precária para não dizer insignificante como expressa a crítica de Chaves feita em 1823:

Não nos consta que haja mais de três homens formados naturaes d'esta Província, e quatro meninos em Coimbra. Esta falta de gosto pelas sciencias, não se pode ter com tudo como inaptidão para ellas nos naturaes; mas antes são doptados de grande engenho. Muitas causas poderemos descubrir a esta falta de homens de letras, e as principaes nos parecem ser. $1^{\circ}$ A falta de eschollas até de primeiras letras. Quem diria que em toda esta província até 1800 havia uma única aula de latim, a de Porto Alegre, e que não havia uma escola de primeiras letras paga pelo Estado em toda a província! Em 1821 abriu-se uma aula de Filosofia Racional em Porto Alegre, e duas de latim no Rio Grande e em Rio Pardo. E as aulas de primeiras letras que se mandavam criar nas freguesias ninguém as tem querido, porque o honorário é só de $100 \$ 000$ e com menos de $400 \$ 000$ não se pode achar um mestre. (1922, p.179).

A situação do ensino nos primeiros tempos esteve de fato abandonada, muitas vezes, entregue somente a iniciativa particular. Por descaso, incompetência, falta de verbas e/ou condições materiais, é perceptível a ausência do poder público em relação à instrução. Esse hiato será parcialmente preenchido pelo ensino particular. Para Augusto Porto Alegre, a instrução primária começa a ser exercida regularmente em Porto Alegre em 1778, quando da abertura da escola para meninos exercida pelo professor Manoel Simões Xavier (PORTO ALEGRE, 1906, p.68).

Quanto à instrução pública, diversos pesquisadores apontam a iniciativa de José Marcelino de Figueiredo, ao estabelecer a primeira escola pública em 02.02.1778, com a 
criação do Colégio Servas de Maria na Aldeia de N. S. dos Anjos, dirigido pela professora D. Gregória Rita Coelho de Mendonça. Dessa data em diante proliferam diversas iniciativas. Em relação ao ensino secundário, pode ser registrado o caso de Vitorino Pereira Coelho, nomeado em 1791 para o cargo de substituto da cadeira de gramática latina para o Rio Grande, com o ordenado de $240 \$ 000$, professor que posteriormente transferiu-se para Porto Alegre. A mesma matéria dispunha, em 1800, de outra aula regida pelo padre Thomé Luiz de Souza. Também é nomeado para a cadeira de latim na capital João Fernandes Tavares em 4 de novembro de 1820, e ainda o padre-mestre João de Santa Bárbara para a cadeira de Filosofia, em 6 do mesmo mês e ano. (PORTO ALEGRE, 1906; DOCCA, 1954).

A instrução pública na Província tem início em 1820, com a nomeação de seus primeiros professores régios ${ }^{4}$. O primeiro professor nomeado para Porto Alegre foi Francisco Pedro de Miranda e Castro, para o ensino das primeiras letras, em 27.07.1820. Seguem, para Porto Alegre, por ordem cronológica: João Fernandes Tavares, para a cadeira de latim, em 04.11.1820; padre de Santa Bárbara, para a cadeira de filosofia, em 06.11.1820; Francisco Alves de Macedo Pereira, para a cadeira de filosofia, em 19.11.1824; Lourenço de Souza Ferreira, para a mesma cadeira em 16.07.1824; Luiz Lourenço Anchois Delavalée, para a cadeira de francês, em 16.07.1824; Manuel Ferraz Pimenta, primeiras letras, em 16.07.1824. Para Rio Pardo foram nomeados: Joaquim Thomaz de Bem Salinas, para primeiras letras em 25.10.1820; Gaspar Francisco Gonçalves, para a cadeira de latim, em 04.11.1820. (PORTO, 1935; p.531).

O modelo de Aulas Régias marcou de certa forma o perfil educacional brasileiro, expressões como "aulas" possuíam o mesmo significado de "classes"; assim como "escola" era utilizada no sentido de "cadeira"; professor era o "mestre-escola"; entre outros.

\section{O Período Imperial}

Em 1830, pelo Relatório apresentado ao Conselho Geral por Caetano Maria Lopes Gama, toma-se a iniciativa de desenvolver a instrução pública particularmente no que diz respeito ao ensino de primeiras letras, com a criação de 28 cadeiras. Contudo o ensino secundário na Província continuava estruturado em aulas avulsas e na mão da iniciativa privada. O Relatório demonstra que não apenas de instrução primária carece a Província, como há uma falta premente de instrução secundária para os jovens que buscam fazer os preparatórios com a finalidade de frequentarem um curso superior. (RPP, 1830, p.69).

Não é muito diferente a análise da situação da instrução pública feita por Galvão (RPP, 1831, p.81), dois anos após, onde a instrução pública oferece um quadro desagradável, "[...] uma só escola de primeiras letras existe em toda a Província, também uma única de latim e outra de geometria, não obstante da primeira classe estarem criadas nove e propostas dezenove; a falta de professores para o ensino da mocidade além de sobremaneira sensível, quase que desanima".

Pela lei de agosto de 1834, conhecida como Ato Adicional, por alterar a constituição de 1824, entre outras medidas, determinava a supressão do poder moderador, o fim do Conselho de Estado, e criação das Assembleias Provinciais; mas os presidentes de Província continuariam sendo nomeados pelo centro. $\mathrm{O}$ art. $10^{\circ}$ determinava a competência das Assembleias, em seu $\S 2^{\circ}$ era autorizado legislar: "[...] sobre instrução pública e estabelecimentos próprios e promovê-la, não compreendendo as faculdades de Medicina, 
os cursos jurídicos, academias atualmente existentes e outros quaisquer estabelecimentos de instrução que para o futuro forem criados por lei geral" 5 .

Pelo Ato Adicional, os Conselhos Gerais das Províncias foram substituídos pelas Assembléias Legislativas com amplíssimas competências. Mas o sistema político continuava a não dar, às elites dominantes regionais, o controle do aparelho administrativo, uma vez que o presidente da província continuava a ser de nomeação imperial. (PICCOLO, 1979, p.98).

Estabelecia-se desse modo, pelo artigo $10^{\circ}$, uma dualidade de competências, permitindo na prática o surgimento de dois sistemas educacionais, o provincial e o controlado pela Corte. Essa realidade marcou profundamente o contexto educacional na Província. Mesmo com o fim da Revolução Farroupilha, o atraso em matéria de educação continuava preocupando as autoridades públicas. É o que expõe o Presidente da Província, Manoel Antônio Galvão perante a Assembleia Legislativa:

A penúria de instrução era imensa no momento da pacificação; moços já adultos eram no genuíno sentido da palavra, analfabetos, e nem a lida da guerra dava repouso às famílias, e no meio desse bulício universal da Província, quem se aventuraria a separar de si os filhos, os parentes, e quando o ousassem, onde os mestres? (RPP, 1847, p.10).

Essa situação permite aventar alguns dos fatores que verdadeiramente entravavam o pleno desenvolvimento da instrução pública. Primeiramente, verifica-se que a estrutura econômica da Província, em grande parte dependente da exportação de matéria prima de produtos oriundos da pecuária extensiva e os fabricados nas charqueadas, não permitia uma inserção maior na economia brasileira. Com uma economia dependente, ficava marginalizada nas decisões hegemônicas, sendo essa uma das grandes razões do movimento armado entre 1835 e 1845.

Essa realidade acabava criando uma pequena elite culta e abastada que podia se dar o luxo de ter a sua formação realizada fora no Estado e às vezes do próprio país, caso emblemático do próprio Gonçalves Chaves, que teve a sua formação acadêmica realizada em Coimbra. Quanto ao resto da população, bastava quando muito, leves rudimentos do ato de escrever, ler e contar, que facilmente podiam ser supridos por poucos indivíduos e, normalmente, da iniciativa particular.

Embora a seriedade, responsabilidade e tentativas de incrementar a educação na Capitania de São Pedro, a precariedade das condições, a falta de verbas, as dificuldades de transporte, os baixos salários dos professores, com certeza eram impedimentos fortes para que a educação não prosperasse.

\section{Considerações}

Dado o exposto, podemos perceber que a Província de São Pedro do Rio Grande do Sul teve sua formação repleta de lutas e disputas políticas, sendo a instrução uma preocupação pequena ou quase esquecida. Logo, entre os anos de 1770 a 1834 a província apresenta um cenário educacional precário. Poucos eram os profissionais da educação 
habilitados. Com efeito, essa lacuna foi durante um longo período suprida pelos padres da Igreja Católica, que efetuavam aulas-régias de primeiras letras na localidade.

Nessa perspectiva, na busca pela apresentação desse panorama, em um primeiro momento discorremos sobre a formação da Província de São Pedro, que se deu por meio de uma forte expressão do poder luso. Primeiramente pelo paulatino processo de ocupação de terras e após com as doações de sesmarias. Assim, originando um espaço rural com forte presença das estâncias, que eram vastas extensões de latifúndios afastados dos núcleos urbanos. Nesse cenário, a elite latifundiária, que tinha um grande poder de mando, não tinha interesse em relação à instrução. Logo, foi possível perceber que o número de professores nessa sociedade era irrisório.

Por conseguinte, observamos o período das aulas-régias, quando em um contexto desfavorável alguns mestres atuavam nas vilas ministrando aulas. Nesse ponto, enfatizamos a administração de Paula Gama, enquanto ação do poder público, que por meio de um posicionamento vigoroso reivindicava a criação de aulas de ler, escrever e contar em Porto Alegre, Rio Grande e Rio Pardo.

Em relação aos anos correspondentes ao Império, até 1834, lembramos que no os respingos da independência acarretaram na busca por uma identidade e em novas responsabilidades e reflexões. Porém a instrução permaneceu como um âmbito sem grande importância. Com a Constituição de 1824 , as províncias permaneciam sob o controle do império, através de seus presidentes. Em 1830, toma-se a iniciativa de desenvolver a instrução pública particularmente no que diz respeito ao ensino de primeiras letras, com a criação de 28 cadeiras. No entanto, a educação em sua grande maioria era um espaço prioritariamente privado e sem uma vasta gama de profissionais. Fato que se tornou preocupante a medida que passou a ser notório que na região não havia meios de preparar os sujeitos para os exames preparatórios com a finalidade de frequentarem um curso superior.

Nesse sentido, por meio do Ato Adicional de 1834 que concedia poder legislativo aos conselhos provinciais, que anteriormente eram um dos maiores focos de reivindicações, foi outorgada uma maior liberdade de atuação. Em contrapartida foi criada uma dualidade de poderes que ocasionou em conflitos e poucos avanços em relação à instrução.

Por fim, destacamos a importância da ação dos dirigentes do poder na esfera educacional que se mostrou quase nula nesse trabalho. Existiram contestações por meio de relatórios e ofícios, mas poucos foram aqueles que buscaram soluções aos problemas. Fato que torna não apenas interessante, mas agregadora a discussão sobre os mestres-escola, que em um período de poucos recursos iniciaram a disseminação do ensino, bem como contribuíram enquanto atores sociais para a notoriedade da lacuna existente no ensino público.

\section{Referências}

ABREU E SILVA, Florêncio de. Retrospecto Econômico e Financeiro do Rio Grande do Sul (1822-1922). In: Revista do Arquivo Público do Rio Grande do Sul. Porto Alegre: Livraria do Globo, $n^{\circ} 8,1922$.

BOTO, Carlota. Iluminismo e educação em Portugal: o legado do século XVIII ao XX. In: STEPHANOU, Maria; BASTOS, Maria Helena C. (Org). Histórias e Memórias da Educação no Brasil. Vol. 1. Petrópolis: Vozes, 2004. 
CARDOSO, Tereza F. L. As aulas régias no Rio de Janeiro: do projeto à prática (17591834). In: História da Educação. Vol. 3. Nº 6. Pelotas: ASPHE, 1999.

CARVALHO, José Murilo de. A construção da ordem: a elite política imperial; teatro de sombras: a política imperial. $2^{\circ}$ ed. Rio de Janeiro: Editora UFRJ \& Relume-Dumará, 1996.

CHAVES, Antonio José Gonçalves. Memórias ecônomo-politicas [01-185]. Revista do Instituto Histórico e Geográfico do Rio Grande do Sul. Ano II. II e III trimestre. N ${ }^{\circ}$ 06/07. Porto Alegre: Typographia do Centro, 1922.

DOCCA, E. F. de Souza. História do Rio Grande do Sul. Rio de Janeiro: Organizações Simões, 1954.

GAMA, Paulo José da Silva, Capitania de São Pedro do Rio Grande (Correspondência do Governador (1802-1809). Coord. Márcia Eckert Miranda; Liana Bach Martins. Porto Alegre: Corag, 2008.

MAGAlHÃES, Manoel Antônio de. Almanak da Villa de Porto Alegre, com reflexões sobre o estado da Capitania do Rio Grande do Sul [51-71]. Revista do Instituto Histórico e Geográfico do Rio Grande do Sul. Ano XX. III trimestre. No 79. Porto Alegre: Livraria do Globo, 1940.

MENDES JR, Antonio et ali. Brasil História: Império (Texto e Contexto). São Paulo: Brasiliense, 1977.

MIRANDA, Márcia Eckert. Continente de São Pedro: administração pública no período colonial. Porto Alegre: Corag, 2000.

PICOLLO, Helga Landgraf. A política rio-grandense no império. In: DACANAL, José H; GONZAGA, Sergius (Org). RS: Economia \& Política. Porto Alegre: Mercado Aberto, 1979.

PINHEIRO, José Feliciano Fernandes. Annaes da Capitania de S. Pedro. Tomo I. Rio de Janeiro: na Impressão Regia, 1819.

Annaes da Província de S. Pedro. Tomo II. Lisboa: Imprensa Nacional, 1822.

PORTO AlEGRE, Augusto. A Fundação de Porto Alegre. Porto Alegre: Typographia da Livraria do Globo, 1906.

PORTO, Aurélio. Notas ao Processo dos Farrapos. Volume III. Rio de Janeiro: Publicações do Arquivo Nacional, 1935.

Relatório ao Conselho Geral apresentado por Caetano Maria Lopes Gama, 1830. In: ROCHE, Jean. L'administration de la Province du Rio Grande do Sul de 1829 à 1847. Porto Alegre: Universidade do Rio Grande do Sul, 1961. 
Relatório ao Conselho Geral apresentado por Manoel Antônio Galvão, 1831. In: ROCHE, Jean. L'administration de la Province du Rio Grande do Sul de 1829 à 1847. Porto Alegre: Universidade do Rio Grande do Sul, 1961.

ROSA, Othelo. Notas sobre a evolução do ensino no Rio Grande do Sul [175-180]. Revista do Instituto Histórico e Geográfico do RGS. No 109/112. Porto Alegre: Oficinas Gráficas da Imprensa Oficial, 1948.

SAINT-HILAIRE, Auguste de. Viagem ao Rio Grande do Sul. Porto Alegre: Erus; Martins Livreiro, 1987.

SOUZA, Francisco Ferreira de. Descrição a viagem do Rio Grande. In: Anais do Simpósio Comemorativo do Bicentenário da Restauração do Rio Grande (1776-1976). Vol. III. Rio de Janeiro: IHGB, 1979.

VASCONCELLOS, Luiz de. Relatório apresentado ao governo de Lisboa pelo ViceRio Luiz de Vasconcellos, em outubro de 1784, sobre o Rio Grande do Sul. Revista do Instituto Histórico e Geográfico do Rio Grande do Sul. Ano IX. I e II trimestre. Porto Alegre: Typographia do Centro, 1929. [03-48].

VERNEY, Luís António. Verdadeiro método de estudar. Porto: Domingos Barreira Editor, s/d.

\footnotetext{
${ }^{1}$ Professor da Universidade Federal de Pelotas (PPGE -FaE- UFPEL). Doutor em Educação pela Pontifícia Universidade Católica do Rio Grande do Sul (PUCRS). Mestre em História pela Pontifícia Universidade Católica do Rio Grande do Sul (PUCRS). Graduado em História pela Universidade Católica de Pelotas (UCpel). Graduado em Direito pela Universidade Federal de Pelotas (UFPEL).
}

\footnotetext{
${ }^{2}$ Mestranda pelo Programa de Pós-Graduação em Educação da Universidade Federal de Pelotas (PPGEUFPEL), na linha de História da Educação, sob orientação do Prof.Dr. Eduardo Arriada. Bolsista-CAPES. Graduada em História-Bacharelado pela Universidade Federal do Rio Grande-FURG. Graduada em HistóriaLicenciatura pela Universidade Federal do Rio Grande-FURG.
${ }^{3}$ Antes de assumir como Presidente da Província (08.03.1824), Fernandes Pinheiro, futuro Visconde de São Leopoldo, ocupou no período da Capitania os cargos de auditor dos regimentos, procurador da Coroa e fiscal da Junta da Fazenda. Vivência que possibilitou a redação da obra: "Anais da Capitania de São Pedro", Tomo I, 1819, e "Anais da Província de São Pedro", Tomo II, 1822.
${ }^{4}$ Em 1816 havia sido pelo governo da Capitania dirigido um memorial, pedindo o estabelecimento de aulas, na Capitania, que não teve despacho algum.

${ }^{5}$ Lei $\mathrm{n}^{\circ}$ 16, de 12 de agosto de 1834 (apud MENDES JR, 1977: 219).
} 